\section{REDUCTION OF ARSENIC.}

\section{To the Editor of THE IANCET.}

Sir :-In THE LANCET of the 19th inst. there are some remarks from Dr, Wilks, respecting a modification of Marsh's arseniuretted hydrogen test. Dr. Wilks considers his apparatus to be a simplification of the original instrument; but $T$ have been in the habit of seeing the test applied in a much more simple manuer. A two or three ounce bottle is supplied with a cork that accurately fits it, and through this cork is inserted about three inches of the stem of a new tobacco-pipe. The solution containing arsenious acid is put into the bottle, together with the necessary portion of dilnte sulphuric acid and zinc. The cork is then replaced, and, after waiting a second or two to allow the atmospheric air in the bottle to be dis. placed, the gas which issues (i.e. arseniuretied hydrogen) may be inflamed, and the arse. nions acid which results from the combustion collected on any proper surface. For this purpose a plate of mica is the best thing that can be employed; but in the country this can but seldom be procured, and a piece of broken Florcnce flask answers every purpose; I believe this form of apparatus was first suggested by Mr. Pereira. Some practical experience enables me to a firm that it is quite a mistake to suppose that the arseniuretted bydrogen will all be dissipated whilst we are waiting for the escape of atmospheric air from the bottle. I $\mathrm{min}$, Sir, your obedient servant,

\section{JOIN SCOFFER. \\ 10, President-street, West, King-square, February 1, 1839.}

\section{ACTION OF THE ALKALIES ON THE BLOOD.}

\section{To the Editor of THE LANeET.}

SIR:-Will you allow me once argain to occupy a small space in your Journal with some facts bearing in the most direct manner on the doctrines broached in the lectures by M. Magendie now in conrse of publication. The passage containing them is from Huxham's " Lssay on Fevers," a work to which, I find, M. Magendie himself alludes in his lecture of to-day.

"Those who accustom themselves to take largely of volatile and fixed alcalious salts, spices, and aloetics, are always subject to these maladies (hæmorrhage and dissolved conditions of the blood). Not a few of those who took the alcalious hoteh-potch of MIrs. Stephens and soaplecs, for a long time together, fell into hectical heats, a hot scurvy, bæomorrhage, dysentery, \&c." The author then adds the case of a gentleman affected with calculus, in which he was himself consulted. The patient, after a course of lixirium, for several weeks, actually found his gums grow spongy, inflamed and livid, sore and putrid; livid spots also appeared on him, and his legs and thighs became of a clurct colour. He died about a fortnight after, in a tabid state, and a calculus weigh. ing 3 viij 3ss. Was found in the bladder. Huxham ascribes the whole train of dis. orders to "an alcalescent putrid state of the lumours, and a dissolution of the blood, from the course of alkalies the patient had gone through."-Edition 1769, p. 47.

I beg to submit this extract to the meditation of your readers, with the simple remark that Huxham was eminently a practical man. I am, Sir, yours,

January 19, 1839.

Suvm Cumane.

\section{ENORMOUS DOSES}

or

\section{ACETATE OF MORPHIA AND TINC. TURE OF OPIUM.}

\section{To the Editor of Tur LaveET.}

Sin:-In reply to an inquiry in a late number of Tre LaNCET, respecting what have been the largest doses of acetate of morphia which have been given to adult persons, I shall feel obliged by your permitting me to state that $I$ an acquainted with a gentleman who, for years, has been in the habit of taking opium for a disease of the spinal chord, attended $w i t h$ violent spasms of the muscles of the chest, abdomen, and inferior extremities, and who, every night for several months, took six grains of acetate of murphia, and, on one occasion, 25 grains of this medicine, divided into four doses, in the course of 24 hours. From the first to the seventh of $\mathbf{J u l y}$, a period of seven days, this gentleman took 540 grains of the extract of opium, and in the course of last year the enormous quantily of $\mathbf{2 4}$ quarts, one pint, 2 ounces, and 50 minims, of the tincture of opium. His usual dose of the tincture of opium is half an ounce, and what appears rather extraordinary, is the circumstance of the largest dose of morphia or opium having never procured beyond an hour's sleep, and the use of the medicines being unaccompanied by diminution of appetite or constipation of bowels. I remain, Sir, your ubedient servant,

\section{Willah Tebian,}

23, Bryanston-square, Jan. 17, 1839. 